động mạch tiểu não trước trên và thần kinh V bền trái. Sau phẫu thuật diễn biến thuận lợi, các biểu hiện lâm sàng được cải thiện rõ rệt, đồng thời về mặt hình ảnh cũng không còn biểu hiện xung đột thần kinh mạch máu trên phim cộng hưởng từ.

\section{KẾT LUẬN}

Xung đột thần kinh mạch máu là nguyên nhân gây đau dây $V$ nhiều nhất ở người trưởng thành. Mặc dù các biểu hiện lâm sàng có vai trò quan trọng trong chẩn đoán, chúng tôi cũng khuyến khích việc sử dụng các phương tiện chẩn đoán hình ảnh, đặc biệt là cộng hưởng từ có giá trị cao trong chẩn đoán và chẩn đoán phân biệt, bền cạnh đó còn góp phần lên kế hoach cho phẫu thuật. Mặt khác việc cân nhắc phấu thuật giải áp cũng là một phướng án hiệu quả để giảm đau cho bệnh nhẩn khi các phương pháp điều trị nội khoa không mang lại kết quả tốt.

TÀI LIỆ THAM KHẢO
1. Haller S., Etienne L., Kövari E. và cộng sự. (2016). Imaging of Neurovascular Compression Syndromes: Trigeminal Neuralgia, Hemifacial Spasm, Vestibular Paroxysmia, and Glossopharyngeal Neuralgia. AJNR Am J Neuroradiol, 37(8), 1384-1392.

2. Leal P.R.L., Froment J.-C., và Sindou M. (2010). MRI sequences for detection of neurovascular conflicts in patients with trigeminal neuralgia and predictive value for characterization of the conflict. Neurochirurgie, 56(1), 43-49.

3. Hughes M.A., Frederickson A.M., Branstetter B.F. và cộng sự. (2016). MRI of the Trigeminal Nerve in Patients With Trigeminal Neuralgia Secondary to Vascular Compression. AJR Am J Roentgenol, 206(3), 595-600.

4. Baldauf J., Rosenstengel $C_{\text {., }}$ và Schroeder H.W.S. (2019). Nerve Compression Syndromes in the Posterior Cranial Fossa. Dtsch Arztebl Int, 116(4), 54-60.

5. Fink R. (2000). Pain assessment: the cornerstone to optimal pain management. Proc (Bayl Univ Med Cent), 13(3), 236-239.

6. Childs A.M., Meaney J.F., Ferrie C.D. và cộng sư. (2000). Neurovascular compression of the trigeminal and glossopharyngeal nerve: three case reports. Arch Dis Child, 82(4), 311-315.

\title{
XÁC ĐỊNH THIẾT BI VÀ PHƯƠNG PHÁP PHÂN TÍCH CHUẨN CHO SÁU THÔNG SỐ HÓA SINH AST, ALT, CHOLESTEROL, TRIGLYCERIDE, GLUCOSE VÀ PROTEIN
}

\section{Trần Hữu Tâm*, Trương Quân Thụy*, Võ Ngọc Nguyên*, Vũ Đình Dũng*, Nguyễn Thị Hồng Phương*, Nguyễn Đức Quỳnh Nhu**, Vũ Thị Như Oanh*, Lê Thị Thùy Nhu*, Nguyễn Ngọc Cường*. \\ AMS Diagnostics, Agappe, Spinreact. \\ Tư khóa: thiết bị chuẩn, vật liệu tham chiếu, phương pháp chuẩn, phương pháp tham chiếu. \\ SUMMARY \\ IDENTIFY STANDARD ANALYTICAL \\ EQUIPMENTS AND METHODS FOR SIX \\ CHEMICAL PARAMETERS AST, ALT, CHOLESTEROL, TRIGLYCERIDE, GLUCOSE AND PROTEIN}

\section{TÓM TẮT}

Các xét nghiệm AST, ALT đại diện cho các bệnh về gan, xét nghiệm Glucose đại diện cho các bệnh về tiểu đường, Protein toàn phần đại diện cho các bệnh về chức năng thân, xét nghiêm Cholesterol và Triglyceride đại diện cho các bệnh về rối loạn chuyển hóa lipid và xơ vữa đông mach $[1,2,3]$. Nghiên cứu nhằm xác định thiết bị và phương pháp phân tích chuẩn cho 6 thông số dựa trên phương pháp tham chiếu và vật liệu tham chiếu. Kết quả nghiên cứu xác định được phương pháp chuẩn cho xét nghiệm AST, ALT là Trisbuffer without pyridoxal-5-phosphate, Glucose là Glucose oxidase, Protein toàn phân là Biuret reaction, Cholesterol là Cholesterol oxidase, Triglyceride là Lipase/GPO-PAP no correction, các thiết bị được sử dụng là các thiết bị của Abbott, Beckman Coulter, Erba Mannheim, Roche, Chema diagnostic,

*Trung tâm Kiểm chuẩn Xét nghiệm TP.HCM

Chịu trách nhiệm chính: Trần Hữu Tâm

Email: trhuutam@yahoo.com

Ngày nhận bài: 14.5.2021

Ngày phản biện khoa học: 30.6.2021

Ngày duyệt bài: 12.7.2021
AST, ALT tests represent for liver diseases, Glucose test represents for diabetes, Total Protein represents for diseases of kidney function, Cholesterol and Triglycerides tests represent for diseases of duslipidemia and atherosclerosis $[1,2,3]$. The study aimed to identify standard analytical equipment and methods for 6 parameters based on reference methods and reference materials. The research results determined that the standard method for testing AST, ALT is Trisbuffer without pyridoxal-5-phosphate, Glucose is Glucose oxidase, Total protein is Biuret reaction, Cholesterol is Cholesterol oxidase, Triglyceride is Lipase/GPO-PAP no correction, the equipments were Abbott, Beckman Coulter, Erba 
Mannheim, Roche, Chema diagnostic, AMS Diagnostics, Agappe, Spinreact.

Keywords: standard equipment, reference material, standard method, reference method.

\section{I. ĐẶT VẤN ĐỀ}

Để đánh giá, phân tích kết quả xét nghiệm cần có các tiêu chí đáng tin cậy cho việc đánh giá quá trình phát triển phương pháp, được mô tả khi phương pháp được công bố và tái đánh giá khi một phòng xét nghiệm riêng lẻ bắt đầu sử dụng phương pháp [5].

Một số hiệp hội hóa sinh lâm sàng, hiệp hội y học như: IFCC, ILAC, CLSI công bố các phương pháp hoặc quy trình tham chiếu cho từng thông số xét nghiệm. Các phương pháp này được tổng hợp bởi các tổ chức như JCTLM (Joint Committee for Traceability in Laboratory Medicine) và FDA $[4,6]$. Chúng tôi dựa trên cơ sở dữ liệu của JCTLM để xác định các phương pháp và vật liệu tham chiếu cho 6 thông số: AST, ALT, Glucose, Protein tổng số, Cholesterol và Triglyceride, từ đó lựa chọn các thiết bị và phương pháp phân tích chuẩn cho 6 thông số xét nghiệm trên. Các thiết bị và phương pháp chuẩn này sẽ được so sánh và đối chiếu với các thiết bị và phương pháp mà các phòng xét nghiệm đang sử dụng.

\section{II. ĐỐI TƯợNG VÀ PHƯƠNG PHÁP NGHIÊN CỨU \\ 2.1. Đối tượng}

- Cơ sở dữ liệu về vật liêu tham chiếu và phương pháp tham chiếu của JCTLM
- 245 phòng xét nghiệm hóa sinh lâm sàng lâm sàng tình nguyện tham gia tại thành phố Hồ Chí Minh và các tỉnh.

\subsection{Phương pháp}

- Thu thập các số liệu về vật liệu tham chiếu và phương pháp tham chiếu của JCTLM của 6 thông số hóa sinh AST, ALT, Glucose, Protein toàn phần, Cholesterol, Triglyceride.

- Gửi phiếu khảo sát cho 245 phòng xét nghiệm tại thành phố Hồ Chí Minh và các tỉnh.

- Tổng hợp và thống kê để xác định các thiết bị và phương pháp mà các phòng xét nghiệm đang thực hiện.

- Tính toán số liệu dựa trên phần mềm Excel 2010, Stata 10.0 .

\section{KẾT QUẢ NGHIÊN CỨU VÀ BÀN LUÂN}

3.1. Xác định phương pháp chuẩn trong phân tích 6 thông số hóa sinh. Các phương pháp thực hiện cho 6 thông số hoá sinh sẽ được tham chiếu từ các phương pháp khuyến cáo mà các Hiệp hội, tổ chức như JCTLM, FDA đã đưa ra và được các nhà sản xuất mẫu chuẩn, mẫu thử sử dụng để sản xuất các bộ kit thương mại.

Dự trên các tài liệu về vật liệu tham chiếu và phương pháp tham chiếu, chúng tôi thống kê những phương pháp cụ thể được sử dụng tương ứng với các thông số tại bảng 1 , từ đó xây dựng phiếu khảo sát và gửi đến các đơn vị nghiên cứu (245 phòng xét nghiệm tại thành phố Hồ Chí Minh và các tỉnh).

Bảng 1. Các phương pháp/quy trinh đo tham chiêu

\begin{tabular}{|c|c|c|}
\hline $\begin{array}{c}\text { Tên } \\
\text { thông số }\end{array}$ & Phương pháp/quy trình đo tham chiếu & Nguyên tắc/phương pháp đo \\
\hline \multirow{3}{*}{ ALT } & \multirow{2}{*}{$\begin{array}{l}\text { IFCC reference measurement procedure } \\
\qquad\left(37^{\circ} \mathrm{C}\right) \text { for } A L T\end{array}$} & $\begin{array}{l}\text { Kinetic spectrophoto-metry (Tris buffer with } \\
\text { pyridoxal - } 5 \text { - phosphate) }\end{array}$ \\
\hline & & $\begin{array}{l}\text { Kinetic spectrophoto-metry (Tris buffer } \\
\text { without pyridoxal - } 5 \text { - phosphate) }\end{array}$ \\
\hline & Scandinavian Committee on Enzymes (SCE) & Kinetic spectrophoto-metry (Tris buffer, SCE) \\
\hline \multirow{3}{*}{ AST } & \multirow{2}{*}{$\begin{array}{l}\text { IFCC reference measurement procedure } \\
\qquad\left(37^{\circ} \mathrm{C}\right) \text { for AST }\end{array}$} & $\begin{array}{c}\text { Kinetic spectrophoto-metry (Tris buffer with } \\
\text { pyridoxal - } 5-\text { phosphate) }\end{array}$ \\
\hline & & $\begin{array}{l}\text { Kinetic spectrophoto-metry (Tris buffer } \\
\text { without pyridoxal - } 5 \text { - phosphate) }\end{array}$ \\
\hline & Scandinavian Committee on Enzymes (SCE) & Kinetic spectrophoto-metry (Tris buffer, SCE) \\
\hline \multirow{6}{*}{ Glucose } & DGKL reference method for glucose & ID/GC/MS \\
\hline & \multirow{2}{*}{ JSCC reference method } & Enzymatic (Glucose oxidase) \\
\hline & & Enzymatic (Hexokinase) \\
\hline & $\begin{array}{l}\text { University of Ghent reference } \\
\text { method for glucose }\end{array}$ & ID/GC/MS \\
\hline & $\begin{array}{l}\text { NIST reference method } \\
\text { for serum glucose }\end{array}$ & ID/GC/MS \\
\hline & $\begin{array}{l}\text { HSA ID/LC/MS/MS reference } \\
\text { measurement procedure } \\
\text { for glucose in human serum }\end{array}$ & ID/LC/MS/ MS \\
\hline
\end{tabular}




\begin{tabular}{|c|c|c|}
\hline & $\begin{array}{l}\text { NCCL ID LC-MS/MS reference } \\
\text { measurement procedure for glucose }\end{array}$ & $\begin{array}{c}\text { Isotope Dilution Mass; Spectrometry (IDMS), } \\
\text { Liquid Chromatogra-phy } \\
\text { Mass Spectrometry (LCMS) }\end{array}$ \\
\hline & $\begin{array}{l}\text { CDC Hexokinase reference } \\
\text { method for glucose }\end{array}$ & Spectrophotometry \\
\hline \multirow{4}{*}{$\begin{array}{c}\text { Cholestero } \\
\text { I }\end{array}$} & $\begin{array}{c}\text { DGKC reference method for serum } \\
\text { cholesterol }\end{array}$ & ID/GC/MS \\
\hline & CDC Abell-Kendall method for cholesterol & Spectrophotometry (Cholesterol oxidase) \\
\hline & $\begin{array}{l}\text { Isotope dilution of cholesterol } \\
\text { by LCMS, Org-005 }\end{array}$ & Isotope dilution LCMS \\
\hline & $\begin{array}{l}\text { NCCL ID-LC/MS/MS Reference } \\
\text { procedure for serum Cholesterol }\end{array}$ & ID-LC/MS/MS \\
\hline \multirow{2}{*}{ Triglyceride } & $\begin{array}{l}\text { JSCC Recommended } \\
\text { Method for triglyceride } \\
\end{array}$ & $\begin{array}{c}\text { Spectrophotometry (Lipase/ GPO-PAP } \\
\text { no correction) }\end{array}$ \\
\hline & NIST reference method for serum triglyceride & ID/GC/MS \\
\hline \begin{tabular}{|c|} 
Protein \\
toàn phần
\end{tabular} & $\begin{array}{l}\text { IFCC } \\
\text { AACC }\end{array}$ & Biuret reaction, end point \\
\hline
\end{tabular}

Số liệu khảo sát từ 245 phòng xét nghiệm trên địa bàn TP.HCM và các tỉnh cho thây, có $100 \%$ phòng xét nghiệm sử dụng phương pháp Tris buffer with pyridoxal - 5 - phosphate cho xét nghiệm AST và $A L T, 91 \%$ phòng xét nghiệm sử dụng phương pháp Glucose oxidase cho xét nghiệm Glucose, $100 \%$ phòng xét nghiệm sử dụng phương pháp Biuret reaction cho xét nghiệm Protein toàn phần, $100 \%$ phòng xét nghiệm sử dụng phương pháp Cholesterol oxidase cho xét nghiệm Cholesterol và 99,41\% phòng xét nghiệm sử dụng phương pháp Lipase/ GPO-PAP no correction cho xét nghiệm Triglyceride.

Bảng 2. Kềt quả khảo sát phương pháp phân tích 6 thông số hóa sinh tại các phòng xét nghiệm

\begin{tabular}{|c|c|c|}
\hline Tên thông số & Phương pháp đo & $\begin{array}{c}\text { Tỉ lệ \% phương pháp } \\
\text { PXN thực hiện }\end{array}$ \\
\hline \multirow{3}{*}{ ALT } & Tris buffer with pyridoxal - 5 - phosphate & $0 \%$ \\
\hline & Tris buffer without pyridoxal - 5-phosphate & $100 \%$ \\
\hline & Tris buffer, SCE & $0 \%$ \\
\hline \multirow{3}{*}{ AST } & Tris buffer with pyridoxal - 5 - phosphate & $0 \%$ \\
\hline & Tris buffer without pyridoxal - 5 - phosphate & $100 \%$ \\
\hline & Tris buffer, SCE & $0 \%$ \\
\hline \multirow{5}{*}{ Glucose } & ID/GC/MS & $0 \%$ \\
\hline & Enzymatic (Glucose oxidase) & $91 \%$ \\
\hline & Enzymatic (Hexokinase) & $9 \%$ \\
\hline & $\begin{array}{l}\text { Isotope Dilution Mass Spectrometry (IDMS), } \\
\text { Liquid Chromatography Mass Spectrometry (LCMS) }\end{array}$ & $0 \%$ \\
\hline & Spectrophotometry & $0 \%$ \\
\hline \multirow{3}{*}{ Cholesterol } & ID/GC/MS & $0 \%$ \\
\hline & Spectrophotometry (Cholesterol oxidase) & $100 \%$ \\
\hline & Isotope dilution LCMS & $0 \%$ \\
\hline \multirow{3}{*}{$\frac{\text { Triglyceride }}{\text { Protein toàn phần }}$} & Spectrophotometry (Lipase/GPO-PAP no correction) & $99,41 \%$ \\
\hline & ID/GC/MS & $0,59 \%$ \\
\hline & Biuret reaction, end point & $100 \%$ \\
\hline
\end{tabular}

Theo bảng 2, các phương pháp thường quy được thực hiện tại các phòng xét nghiệm khảo sát tương ứng với các phương pháp tham chiếu mà các Hiệp hội, Liên đoàn đã công bố. Các phương pháp này cũng được các nhà sản xuất hoá chất và thuốc thử sử dụng để làm cơ sở cho việc sản xuất các bộ kít thương mại. Các phương pháp đo được xác định cụ thể như sau:

- Xét nghiệm AST, ÁLT: Trisbuffer without pyridoxal-5-phosphate
- Xét nghiêm Glucose: Glucose oxidase

- Xét nghiệm Protein toàn phần: Biuret reaction

- Xét nghiểm Cholesterol: Cholesterol oxidase

- Xét nghiệm Triglyceride: Lipase/GPO-PAP no correction

3.2. Xác định thiết bị chuẩn dùng trong phân tích 6 thông số hóa sinh. Các thiết bị của các nhà sản xuất lớn như Abbott, Beckman, Roche,...thường được sử dụng phổ biến tại các phòng xét nghiệm trên thế giới và Việt Nam 
tương ứng với những bột kít đi kèm của hãng. Kết quả tổng hợp các thiết bị tương ứng với các phương pháp đo thể hiện trong bảng 3.

Bảng 3. Kết quả khảo sát thiết bị và hóa chất sử dụng trong phân tích 6 thông số hóa sinh

\begin{tabular}{|c|c|c|}
\hline $\begin{array}{c}\text { Tên thông } \\
\text { số }\end{array}$ & $\begin{array}{c}\text { Phương pháp } \\
\text { đo }\end{array}$ & Thiết bị sử dụng \\
\hline \multirow{3}{*}{ ALT } & $\begin{array}{l}\text { Tris buffer with } \\
\text { pyridoxal - } 5 \text { - } \\
\text { phosphate }\end{array}$ & $\begin{array}{l}\text { 1. Abbott } \\
\text { 2. Beckman }\end{array}$ \\
\hline & $\begin{array}{c}\text { Tris buffer } \\
\text { without pyridoxal } \\
-5 \text { - phosphate }\end{array}$ & $\begin{array}{l}\text { 1. Roche } \\
\text { 2. Beckman } \\
\text { 3. Chema } \\
\text { diagnostic } \\
\text { 4. Erba Mannheim }\end{array}$ \\
\hline & Tris buffer, SCE & 1. AMS Diagnostics \\
\hline \multirow{3}{*}{ AST } & $\begin{array}{l}\text { Tris buffer with } \\
\text { pyridoxal - } 5 \text { - } \\
\text { phosphate }\end{array}$ & $\begin{array}{l}\text { 1. Abbott } \\
\text { 2. Beckman }\end{array}$ \\
\hline & $\begin{array}{c}\text { Tris buffer } \\
\text { without pyridoxal } \\
-5 \text { - phosphate }\end{array}$ & $\begin{array}{l}\text { 1. Roche } \\
\text { 2. Beckman } \\
\text { 3. Chema } \\
\text { diagnostic } \\
\text { 4. Erba Mannheim }\end{array}$ \\
\hline & Tris buffer, SCE & 1. AMS Diagnostics \\
\hline \multirow[b]{2}{*}{ Glucose } & Glucose oxidase & $\begin{array}{l}\text { 1. Chema } \\
\text { diagmostic } \\
\text { 2. Agappe } \\
\text { 3. Spinreact }\end{array}$ \\
\hline & Hexokinase & $\begin{array}{l}\text { 1. Roche } \\
\text { 2. Abbott } \\
\text { 3. Beckman }\end{array}$ \\
\hline Cholesterol & $\begin{array}{l}\text { Cholesterol } \\
\text { oxidase }\end{array}$ & $\begin{array}{l}\text { 1. Abbott } \\
\text { 2. Beckman } \\
\text { 3. Roche } \\
\text { 4. Spinreact } \\
\text { 5. Chema } \\
\text { diagmostic } \\
\text { 6. Siemiens }\end{array}$ \\
\hline $\begin{array}{c}\text { Triglyceride } \\
\text { Protein } \\
\text { Protein }\end{array}$ & $\begin{array}{l}\text { Lipase/ GPO-PAP } \\
\text { no correction }\end{array}$ & $\begin{array}{l}\text { 1. Abbott } \\
\text { 2. Chema } \\
\text { diagnostic } \\
\text { 3. Beckman }\end{array}$ \\
\hline $\begin{array}{l}\text { Protein } \\
\text { toàn phần }\end{array}$ & $\begin{array}{l}\text { Biuret reaction, } \\
\text { end point }\end{array}$ & $\begin{array}{l}\text { 1. Abbott } \\
\text { 2. Beckman } \\
\text { 3. Roche } \\
\text { 4. Chema } \\
\text { diaanostic }\end{array}$ \\
\hline
\end{tabular}

Như vậy, các thiết bị phân tích được sử dụng phổ biến hiện nay tại các phòng xét nghiệm là Abbott, Beckman Coulter, Erba Mannheim, Roche, Chema diagnostic, AMS Diagnostics, Agappe, Spinreact.

Theo phiếu khảo sát của 245 phòng xét nghiệm gửi về thì các thiết bị được sử dụng phổ biến nhất là các thiết bị của Abbott $(18,37 \%)$,

Beckman Coulter $(24,49 \%)$, Roche $(16,33 \%)$, Erba (10,20\%).

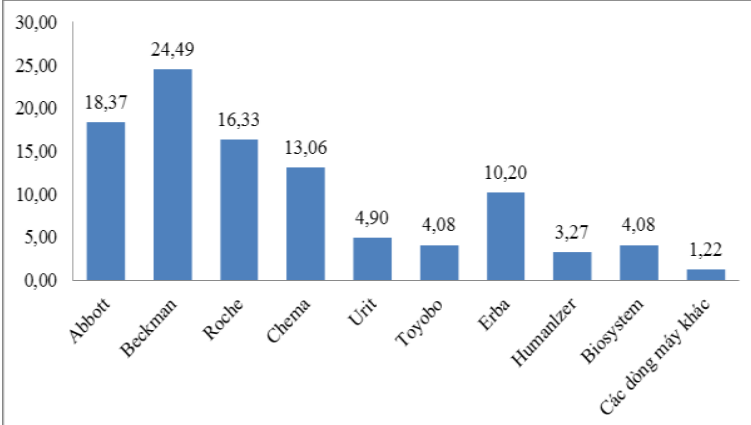

\section{Biểu đồ 1. Tỉ lệ \% các thiêt bị được sử dung tại 245 phòng xét nghiệm}

\section{KẾT LUẬN}

Nghiên cứu đã xác định được các phương pháp chuẩn được sử dụng trong phân tích 6 thông số hóa sinh, cụ thể như sau:

- Xét nghiệm AST, ALT: Trisbuffer without pyridoxal-5-phosphate

- Xét nghiệm Glucose: Glucose oxidase

- Xét nghiệm Protein toàn phần: Biuret reaction

- Xét nghiệm Cholesterol: Cholesterol oxidase

- Xét nghiệm Triglyceride: Lipase/GPO-PAP no correction

Dựa trên các phương pháp chuẩn này, nhóm nghiên cứu cũng xác định được các thiết bị phân tích được các nhà sản xuất hóa chất và thiết bị sử dụng như Beckman Coulter, Abbott, Erba, Roche,...

\section{KIẾN NGH!}

Sử dụng kết quả của nghiên cứu làm tiền đề cho việc chế tạo mẫu ngoại kiểm sinh hóa đáp ứng được các tiêu chuẩn kỹ thuật trong và ngoài nước, góp phần vào việc đảm bảo chất lượng xét nghiệm.

\section{TÀI LIỆ THAM KHẢO}

1. Bộ Y Tế (2013), Thông tư Hướng dẫn thực hiện quản lý chất lượng xét nghiệm tại cơ sở khám bênh, chữa bênh, số 01/2013/īT-BY̛T, Hà Nội.

2. Tạ Thành Vắn (2013), Hoá sinh lâm sàng, Nxb Y Học Hà Nội.

3. Phan Hải Nam (2006), Một số xét nghiệm hoá sinh trong lâm sàng, Học Viện Quân Y.

4. Orlando C. Ferreira, Jr Maria Cristina, F. Pessoa (2006), Metrological traceability in clinical laboratory, J. Bras. Patol. Med. Lab. , 52(3).

5. D Stamm (1979), Reference materials and reference methods in clinical chemistry, J Clin Chem Clin Biochem, 17(5), 283-97.

6. Graham R.D. Jones (2016), Review: The Joint Committee for Traceability in Laboratory Medicine (JCTLM) -its history and operation, Clinica Chimica Acta 453, 86-94. 